\title{
Heat stress and fetal risk. Environmental limits for exercise and passive heat stress during pregnancy: a systematic review with best evidence synthesis
}

\author{
Nicholas Ravanelli, ${ }^{1,2}$ William Casasola, ${ }^{1,3}$ Timothy English, ${ }^{1}$ Kate M Edwards, ${ }^{4}$ \\ Ollie Jay ${ }^{\oplus 1,2,4}$
}

- Additional material is published online only. To view please visit the journal online (http://dx.doi.org/10.1136/ bjsports-2017-097914).

${ }^{1}$ Thermal Ergonomics Laboratory, Faculty of Health Sciences, University of Sydney, Sydney, New South Wales, Australia

${ }^{2}$ School of Human Kinetics, University of Ottawa, Ottawa, Ontario, Canada

${ }^{3}$ Exeter Medical School, University of Exeter, Exeter, UK ${ }^{4}$ Charles Perkins Centre, University of Sydney, Sydney, New South Wales, Australia

\section{Correspondence to} Dr Ollie Jay, Exercise and Sports Science, Faculty of Health Sciences, Thermal Ergonomics Laboratory, University of Sydney, NSW 2141, Australia;

ollie.jay@sydney.edu.au

Accepted 5 January 2018

Published Online First

1 March 2018
Check for updates

To cite: Ravanelli N, Casasola W, English T, et al. Br J Sports Med 2019:53:799-805.

\section{ABSTRACT}

Objective Pregnant women are advised to avoid heat stress (eg, excessive exercise and/or heat exposure) due to the risk of teratogenicity associated with maternal hyperthermia; defined as a core temperature $\left(\mathrm{T}_{\text {core }}\right)$ $\geq 39.0^{\circ} \mathrm{C}$. However, guidelines are ambiguous in terms of critical combinations of climate and activity to avoid and may therefore unnecessarily discourage physical activity during pregnancy. Thus, the primary aim was to assess $T_{\text {core }}$ elevations with different characteristics defining exercise and passive heat stress (intensity, mode, ambient conditions, duration) during pregnancy relative to the critical maternal $\mathrm{T}_{\text {core }}$ of $\geq 39.0^{\circ} \mathrm{C}$.

Design Systematic review with best evidence synthesis. Data sources EMBASE, MEDLINE, SCOPUS, CINAHL and Web of Science were searched from inception to 12 July 2017.

Study eligibility criteria Studies reporting the $T_{\text {core }}$ response of pregnant women, at any period of gestation, to exercise or passive heat stress, were included.

Results 12 studies satisfied our inclusion criteria $(n=347)$. No woman exceeded a $T_{\text {core }}$ of $39.0^{\circ} \mathrm{C}$. The highest $\mathrm{T}_{\text {core }}$ was $38.9^{\circ} \mathrm{C}$, reported during land-based exercise. The highest mean end-trial $\mathrm{T}_{\text {core }}$ was $38.3^{\circ} \mathrm{C}$ $\left(95 \% \mathrm{Cl} 37.7^{\circ} \mathrm{C}\right.$ to $\left.38.9^{\circ} \mathrm{C}\right)$ for land-based exercise, $37.5^{\circ} \mathrm{C}\left(95 \% \mathrm{Cl} 37.3^{\circ} \mathrm{C}\right.$ to $\left.37.7^{\circ} \mathrm{C}\right)$ for water immersion exercise, $36.9^{\circ} \mathrm{C}\left(95 \% \mathrm{Cl} 36.8^{\circ} \mathrm{C}\right.$ to $\left.37.0^{\circ} \mathrm{C}\right)$ for hot water bathing and $37.6^{\circ} \mathrm{C}\left(95 \% \mathrm{Cl} 37.5^{\circ} \mathrm{C}\right.$ to $\left.37.7^{\circ} \mathrm{C}\right)$ for sauna exposure.

Conclusion The highest individual core temperature reported was $38.9^{\circ} \mathrm{C}$. Immediately after exercise (either land based or water immersion), the highest mean core temperature was $38.3^{\circ} \mathrm{C} ; 0.7^{\circ} \mathrm{C}$ below the proposed teratogenic threshold. Pregnant women can safely engage in: (1) exercise for up to $35 \mathrm{~min}$ at $80 \%-90 \%$ of their maximum heart rate in $25^{\circ} \mathrm{C}$ and $45 \%$ relative humidity $(\mathrm{RH})$; (2) water immersion $\left(\leq 33.4^{\circ} \mathrm{C}\right)$ exercise for up to $45 \mathrm{~min}$; and (3) sitting in hot baths $\left(40^{\circ} \mathrm{C}\right)$ or hot/dry saunas $\left(70^{\circ} \mathrm{C} ; 15 \% \mathrm{RH}\right)$ for up to $20 \mathrm{~min}$, irrespective of pregnancy stage, without reaching a core temperature exceeding the teratogenic threshold.

\section{INTRODUCTION}

Seminal work by the late Dr Marshall Edwards provided animal model-based evidence that hyperthermia $\left(41^{\circ} \mathrm{C}-43^{\circ} \mathrm{C}\right)$ during gestation can result in fetal malformations and/or pregnancy complications. ${ }^{1-3}$ Following these studies, retrospective studies in humans demonstrated a greater risk of fetal malformations if severe hyperthermia was attained (primarily through fever) during pregnancy. ${ }^{4-9} \mathrm{~A}$ maternal core temperature exceeding $39.0^{\circ} \mathrm{C}$ (or an elevation of $\sim 1.5^{\circ} \mathrm{C}$ to $2.0^{\circ} \mathrm{C}$ from baseline) has been suggested as the critical threshold for an increased risk for teratogenic consequences to a fetus. $^{10-12}$

Guidelines from the American Congress of Obstetrics and Gynaecologists (ACOG) ${ }^{13}$ the Royal Australian and New Zealand College of Obstetricians and Gynaecologists ${ }^{14}$ and the Royal College of Obstetricians and Gynaecologists ${ }^{15}$ discourage the use of hot water baths and saunas during pregnancy and suggest '...avoiding high heat and humidity to protect against heat stress.' ${ }^{13}$ Without objective definitions, the terms 'hot' and 'humid' environments are ambiguous and subject to a wide scope of individual interpretation that may be further confounded by an altered perception of thermal stimuli with pregnancy. ${ }^{16} 17$

Despite the clear downstream health benefits of exercise during pregnancy to child and mother, ${ }^{18-20}$ only a small proportion of pregnant women meet the recommended physical activity requirements, ${ }^{21} 22$ with hot weather a reported perceived barrier. ${ }^{23}{ }^{24}$ Given that thermoregulatory capacity may be enhanced during pregnancy, ${ }^{11} 25-27$ in most circumstances women may be unnecessarily avoiding physical activity in warm environments due to unfounded concerns about the risk of attaining harmful core temperatures. Thus, identifying the combinations of climatic conditions, and exercise intensity, duration and mode that can be performed without exceeding a critical maternal core temperature of $39.0^{\circ} \mathrm{C}$ is an urgent priority. Assessing the evidence for whether different stages of pregnancy alter thermoregulatory capacity is important for obstetricians and gynaecologists, and other clinicians who might be advising pregnant women about exercise and heat exposure.

The aims of this systematic review were to (1) determine the critical environmental and exposure limits for exercise and/or heat exposure during pregnancy, and (2) assess whether thermoregulatory capacity (indicated by changes in core temperature) during exercise and/or heat exposure is altered throughout pregnancy.

\section{METHODS}

\section{Search strategy}

We followed the Preferred Reporting Items for Systematic Reviews and Meta-Analyses guidelines for reporting systematic reviews. All searches were conducted between 3 October 2016 and 
12 July 2017. We searched the EMBASE, MEDLINE, SCOPUS, CINAHL and Web of Science electronic databases for articles pertaining to thermoregulation during pregnancy. Specifically, two search strategies were used following the PICO format (PICO: P (Population), I (Intervention), C (Comparison), O (Outcome)):

1. A combination of pregnancy terms (P), exercise terms (I) and heat/temperature terms $(\mathrm{O})$.

2. A combination of pregnancy terms $(\mathrm{P})$, hot bath/sauna terms (I) and heat/temperature terms $(\mathrm{O})$.

Search terms were customised for the coding of each database to search title, abstract and keywords and then combined with 'AND' to produce the final search yield (see online supplementary file 1 for the search strategy as applied to MEDLINE with yields at each step). All retrieved articles were exported to reference management software (Endnote V.X7).

\section{Selection of studies}

Titles and abstracts of retrieved articles were independently reviewed by three reviewers (NMR, WC and TE) to assess whether inclusion criteria were met. In the case of uncertainty of inclusion, the full text was retrieved and discussed. Disagreements were resolved by consensus. Reference lists of retrieved articles were also manually searched for additional relevant studies. Following the title and abstract screening, the three reviewers (NMR, WC and TE) independently retrieved the full articles of prospective studies to confirm whether they satisfied the inclusion criteria.

\section{Study inclusion criteria}

We included studies with an experimental (ie, implemented an intervention) design that assessed pregnant women (independent of gestational age). Included studies must have used a thermal stimulus to challenge the thermoregulatory system, and reported at least one index of core temperature as a dependent variable. Studies with or without a non-pregnant control group were included. We included full-text articles published in the English language.

\section{Data extraction}

Participant characteristics (ie, mass, age, weeks of gestation), experimental protocol (ie, exercise intensity, duration, mode and environmental conditions) and core temperature data were extracted by one assessor. Data were checked for accuracy by two independent assessors. For different articles using the same cohort, with no additional findings satisfying the inclusion criteria, the most comprehensive study was included. All core temperature data were extracted and expressed as a mean with 95\% CIs (M (95\% CI)). The change in core temperature was determined as the difference between baseline and at the end of exercise/heat exposure. Data for mean heat production $\left(\mathrm{H}_{\text {prod }}\right)$ expressed in watts (W) during exercise (ie, the net difference between metabolic energy expenditure and external work) were also extracted. If $\mathrm{H}_{\text {prod }}$ was not provided it was estimated using equations from Nielsen and Davies ${ }^{28}$ if the rate of oxygen consumption $\left(\mathrm{VO}_{2}\right)$ was reported. If $\mathrm{VO}_{2}$ was not reported, $\mathrm{VO}_{2}$ was estimated using the American College of Sports Medicine standardised equations, ${ }^{29}$ provided an objective index of external work was provided.

\section{Risk of bias assessment}

Risk of bias was independently assessed by two assessors using the Cochrane Risk of Bias Assessment (ROB) V.2.0 tool for randomised crossover or other matched designs. ${ }^{30}$ Disagreements were resolved by consensus. The individual studies' overall risk of bias was determined using the following modified assessment: low risk of bias: four or more domains with a low risk of bias; some concerns: a minimum of two domains with some concerns, or one domain with some concerns and one high risk of bias; high risk of bias: two or more domains with a high risk of bias.

\section{Best evidence synthesis}

A modified version of the 2009 Centre for Evidence-Based Medicine $\left(\mathrm{CEBM}^{31}\right)$ levels of evidence for interventions was used to synthesise and rank the evidence. Our modified version (I-IV) ranked the source of evidence in the following manner: level I randomised controlled trial, level II cohort study, level III case-control study, level IV a case series or study. Studies were grouped based on the environment of exercise and/or heat stress: (1) land-based exercise, (2) water-based exercise and (3) hot bath or sauna use.

The strength of the evidence included was then evaluated using a modified version of the CEBM 'Grades of Recommendation' using the A-D grading system: A signifies consistent findings in $>2$ level I studies; B signifies consistent findings in $>2$ level II or III studies, or $\leq 2$ level I studies; $C$ signifies consistent findings in $>2$ level IV studies, or $\leq 2$ level II or III studies; D signifies level IV evidence or inconsistent findings, independent of level. Consistency among studies was defined as the core temperature response of pregnant women during heat stress either above or below the $39.0^{\circ} \mathrm{C}$ threshold. The level of evidence in any study was downgraded if a high risk of bias or some concerns were determined using the Cochrane ROB V.2.0 tool.

\section{RESULTS}

We identified 1329 non-duplicate articles for title and abstract screening (EMBASE: 230; MEDLINE: 184; SCOPUS: 184; CINAHL: 55; Web of Science: 676). We screened 18 studies in full text (figure 1). One article was excluded as only an abstract was available ${ }^{32}$; we found two instances of multiple reports from the same cohorts (totalling five articles ${ }^{33-37}$ ) and were included. ${ }^{34} 37$ A total of 12 studies were included in our review. $^{25} 263437-45$

\section{Characteristics of included studies}

The heat stress response of a total of 347 pregnant women was captured. In addition, 26 non-pregnant controls of childbearing age were included. ${ }^{34}$ Three studies had 10 or fewer participants, ${ }^{253739}$ six had 10-20 participants ${ }^{26} 3438404243$ and three studies had more than 50 participants. ${ }^{41445}$ Twenty-nine subgroups were tested across the gestational period and control (figure 2).

\section{Participant characteristics}

Age was reported as either range only $\left(n=2^{26} 37\right.$ ), mean only $\left(n=4^{38} 404243\right)$, range and mean $\left(n=3^{25} 3445\right)$ or unreported $\left(n=2^{3941}\right)$ (online supplementary table S1 and figure 2). Four studies reported participant mass on the day of testing, ${ }^{26} 384244$ two reported the mean mass across gestation and group tested ${ }^{3440}$ and six studies did not report mass. 253739414345 Studies either did not report participant fitness levels $\left(n=2^{4143}\right)$ or objectively defined participants as sedentary $\left(n=2^{42} 45\right)$ or physically active $\left(\mathrm{n}=8^{25} 2637-40424445\right)$. The sole study using saunas stated that participants were accustomed to the practice. ${ }^{34}$ 


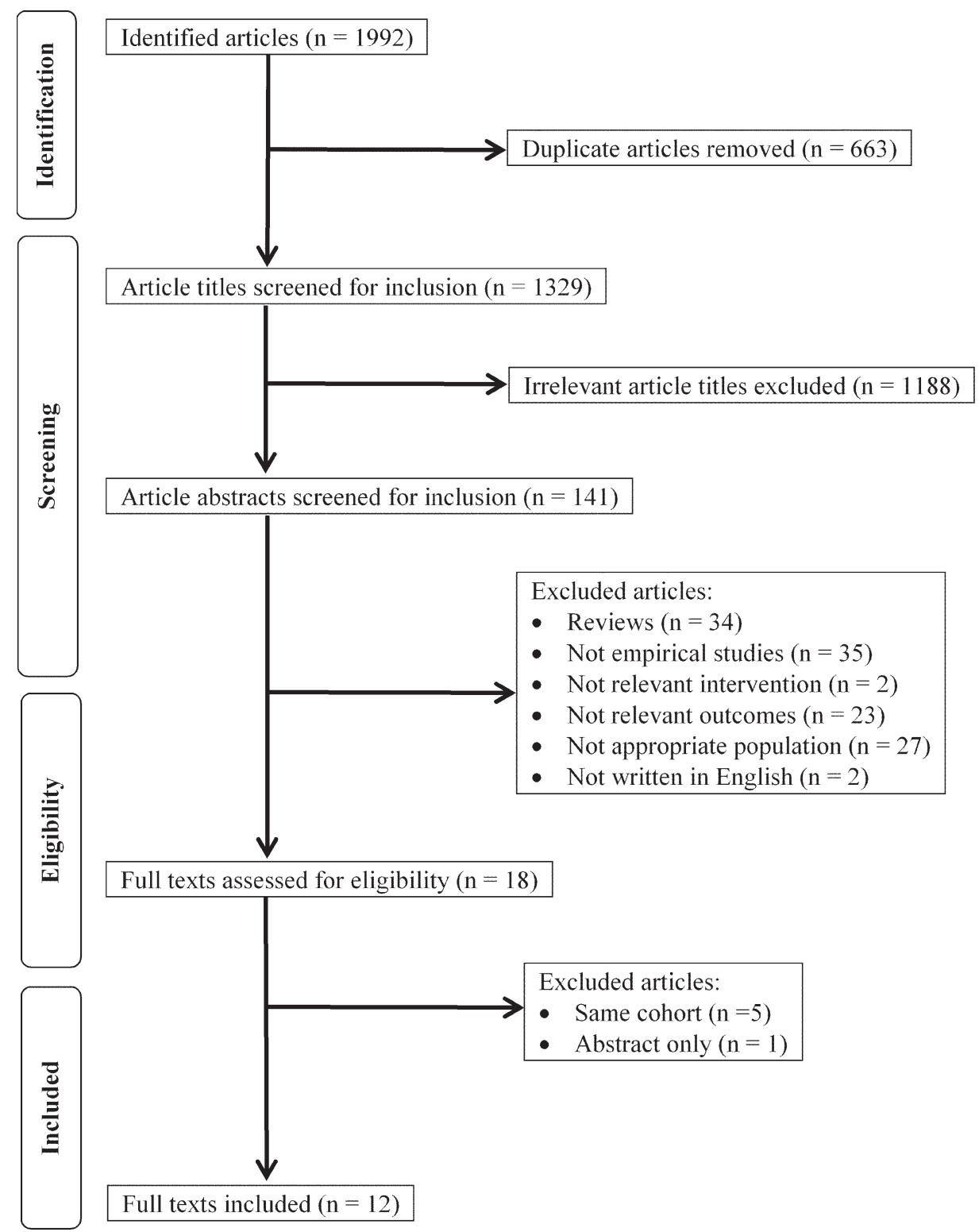

Figure 1 Preferred Reporting Items for Systematic Reviews and Meta-Analyses (PRISMA) diagram showing the selection and exclusion process of papers, including number of articles included in the review.

\section{Heat stress protocols}

The methods to induce heat stress in the included studies were separated into three primary categories: eight studies conducted land-based exercise, ${ }^{25} 263739-43$ three conducted water immersion exercise $\left(n=3^{37} 3845\right)$ and two conducted passive heating at rest $\left(n=2^{3441}\right)$ (online supplementary table S1 and figure 2).

Heat production: 6 of 11 exercise-based studies $252637-3942$ provided sufficient data to extract $\mathrm{H}_{\text {prod }}$, with values provided for a total of 18 groups of pregnant women at various periods of gestation (figure 2). The range of $\mathrm{H}_{\text {prod }}$ was 305-1195 W.

Core temperature: figure 2 illustrates the mean and 95\% CI of the absolute core temperature responses of pregnant women following exercise/heat stress in the included studies. Irrespective of exercise mode, intensity or duration, or type of heat exposure, no study reported any participant exceeding a core temperature above the recommended maternal threshold of $39.0^{\circ} \mathrm{C}$, with $38.9^{\circ} \mathrm{C}$ the highest individual core temperature reported. ${ }^{25}$ The study inducing the highest $\mathrm{H}_{\text {prod }}$ (1195 W; 30 min running by aerobically fit pregnant participants at $80 \%-90 \%$ of $\mathrm{HR}_{\max }$ ) observed mean end-exercise core temperatures of $38.3^{\circ} \mathrm{C}(95 \% \mathrm{CI}$ $37.7^{\circ} \mathrm{C}$ to $38.9^{\circ} \mathrm{C}^{39}$; figure 2$)$. Further, the highest mean core temperature observed during exclusively non-weight-bearing exercise (eg, cycling) on land during pregnancy was $37.6^{\circ} \mathrm{C}$ $\left(95 \% \mathrm{CI} 37.4^{\circ} \mathrm{C}\right.$ to $\left.37.8^{\circ} \mathrm{C}^{37}\right)$. The highest mean core temperature for pregnant women with warm water $\left(30^{\circ} \mathrm{C}\right)$ immersion cycling was $37.5^{\circ} \mathrm{C}\left(95 \% \mathrm{CI} 37.3^{\circ} \mathrm{C}\right.$ to $\left.37.7^{\circ} \mathrm{C}^{38}\right)$. Aqua-aerobic exercise in water temperatures ranging from $28.8^{\circ} \mathrm{C}$ to $33.4^{\circ} \mathrm{C}$ resulted in a mean core temperature of $36.7^{\circ} \mathrm{C}\left(95 \% \mathrm{CI} 36.6^{\circ} \mathrm{C}\right.$ to $36.8^{\circ} \mathrm{C}^{45}$ ). Studies assessing pregnant women during passive heating via sauna or a $40^{\circ} \mathrm{C}$ water immersion reported mean maternal core temperatures peaking at $37.6^{\circ} \mathrm{C}\left(95 \% \mathrm{CI} 37.5^{\circ} \mathrm{C}\right.$ to $\left.37.7^{\circ} \mathrm{C}^{34}\right)$ and $36.9^{\circ} \mathrm{C}\left(95 \% \mathrm{CI} 36.8^{\circ} \mathrm{C}\right.$ to $\left.37.0^{\circ} \mathrm{C}^{41}\right)$, respectively. In general, the rise in core temperature with exercise/heat exposure declined with progressive pregnancy (figure 3 ). The change in core temperature was significantly smaller ${ }^{46} 47$ later in pregnancy compared with a non-pregnant state in three of five land-based exercise studies. However, similar changes in core temperature were observed throughout pregnancy during 


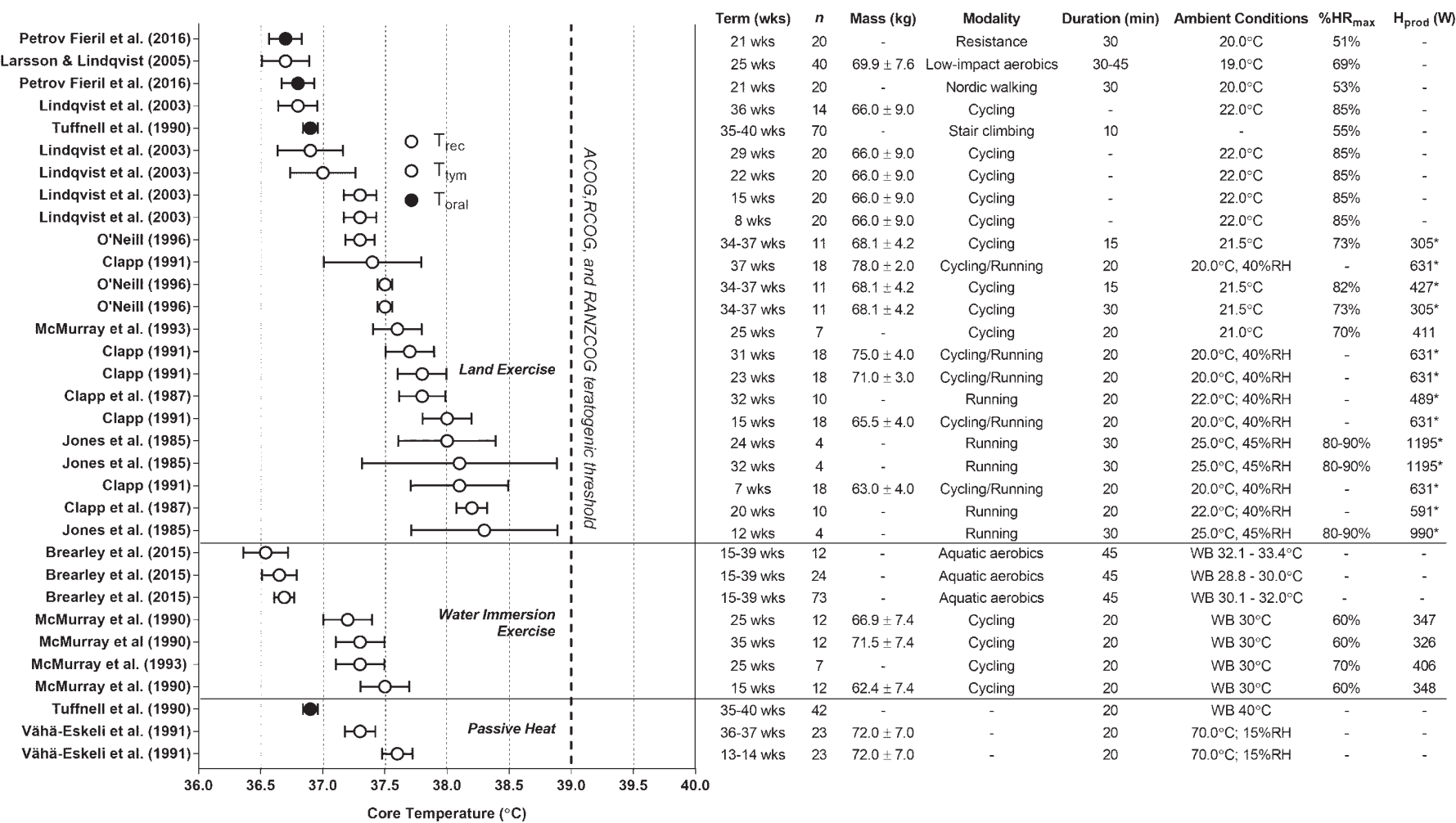

Figure 2 Mean $(95 \% \mathrm{Cl})$ absolute rectal $\left(\mathrm{T}_{\text {rec }}\right)$, tympanic $\left(\mathrm{T}_{\text {tym }}\right)$ or sublingual $\left(\mathrm{T}_{\text {oral }}\right)$ temperature reported following exercise on land or water immersion, and passive heat stress during pregnancy. The modality of exercise, ambient conditions and exercise intensity relative to estimated maximum heart rate $\left(\% \mathrm{HR}_{\max }\right)$ and heat production $\left(\mathrm{H}_{\text {prod }}\right)$ are provided. The black dotted line reflects the teratogenic temperature threshold defined by ACOG, ${ }^{13}$ RCOG $^{15}$ and RANZCOG. ${ }^{14}{ }^{*} \mathrm{H}_{\text {prod }}$ estimation from provided information. ACOG, American Congress of Obstetrics and Gynaecologists; HR, heart rate; RANZCOG, Royal Australian and New Zealand College of Obstetricians and Gynaecologists; RCOG, Royal College of Obstetricians and Gynaecologists; $\mathrm{RH}$, relative humidity; WB, Water Bath.

the one study reporting warm water immersion exercise ${ }^{38}$ and during sauna use. ${ }^{34}$

\section{Risk of bias assessment}

Using our modified Cochrane ROB V.2.0 tool, six studies (out of 12) had some concerns about $(n=5)$ or were at high risk $(n=1)$ of selection bias, ${ }^{39}$ detection bias ${ }^{45}$ and intervention bias. ${ }^{25} 264042$

\section{Best evidence synthesis}

There is level B evidence to support the low risk of maternal core temperature exceeding $39.0^{\circ} \mathrm{C}$ during land-based exercise, independent of gestational age and modality (eg, running, cycling, aerobics, resistance), and at intensities up to $90 \%$ of $\mathrm{HR}_{\max }$ by fit pregnant women for up to $35 \mathrm{~min}$, in ambient conditions not exceeding $25^{\circ} \mathrm{C}$ and $45 \%$ relative humidity (RH). This recommendation is supported by six studies with level II-III evidence and two studies with level IV evidence (online supplementary table S2).

There is level $\mathrm{C}$ evidence to support the low risk of maternal core temperature exceeding $38.0^{\circ} \mathrm{C}$, during aquatic-based cycling or aerobics lasting 20 and $45 \mathrm{~min}$, respectively, in water temperatures up to $33.4^{\circ} \mathrm{C}$ by pregnant women, independent of gestational age. This recommendation is supported by three studies ranging from level I to level III evidence (online supplementary table S2).

There is level $\mathrm{D}$ evidence to support the low risk of maternal core temperature exceeding $38.0^{\circ} \mathrm{C}$, during passive heat exposure to warm baths $\left(40.0^{\circ} \mathrm{C}\right)$ or sauna use $\left(70.0^{\circ} \mathrm{C}, 15 \% \mathrm{RH}\right)$ for up to $20 \mathrm{~min}$. This recommendation is supported by two studies ranging from level II to level IV evidence (online supplementary table S2).

\section{DISCUSSION}

Our systematic review suggests that pregnant women can participate in up to $35 \mathrm{~min}$ of very high-intensity aerobic exercise $\left(\sim 90 \% \mathrm{HR}_{\max }\right)$ at air temperatures of up to $25^{\circ} \mathrm{C}$ and $45 \% \mathrm{RH}$ without attaining or exceeding a core temperature of $39.0^{\circ} \mathrm{C}$; the hypothesised teratogenic threshold during pregnancy. ${ }^{10-12}$ Similarly, no study has ever reported the core temperature of a pregnant woman to exceed $38.0^{\circ} \mathrm{C}, 1.0^{\circ} \mathrm{C}$ lower than the critical maternal core temperature, when exercising in a warm bath $\left(30^{\circ} \mathrm{C}^{37}{ }^{38}\right)$ or during resting exposure to a hot and dry sauna $\left(70^{\circ} \mathrm{C} ; 15 \% \mathrm{RH}^{34}\right)$ or immersion in a $40^{\circ} \mathrm{C}$ water bath ${ }^{41}$ for up to $20 \mathrm{~min}$. Change in core temperature during exercise/heat exposure appears to decline with progressive pregnancy (figure 3).

While the downstream benefits to the children of pregnant women who engage in regular physical activity prior to and throughout pregnancy have been well documented, ${ }^{18-20}$ exercise inevitably results in the production of heat, which must be liberated to the environment to mitigate the rise in internal temperature. The excess heat produced from muscular contractions is first transferred to the surrounding tissue by a combination of conduction and convection through the circulatory system where it will ultimately be dissipated from the skin surface to the surrounding environment through dry or evaporative (ie, sweating) avenues. The temperature gradient for heat transfer flows from fetus to mother at rest, but this gradient is reversed during exercise. ${ }^{48}$ 


\section{O Pregnant \\ O Non-Pregnant}

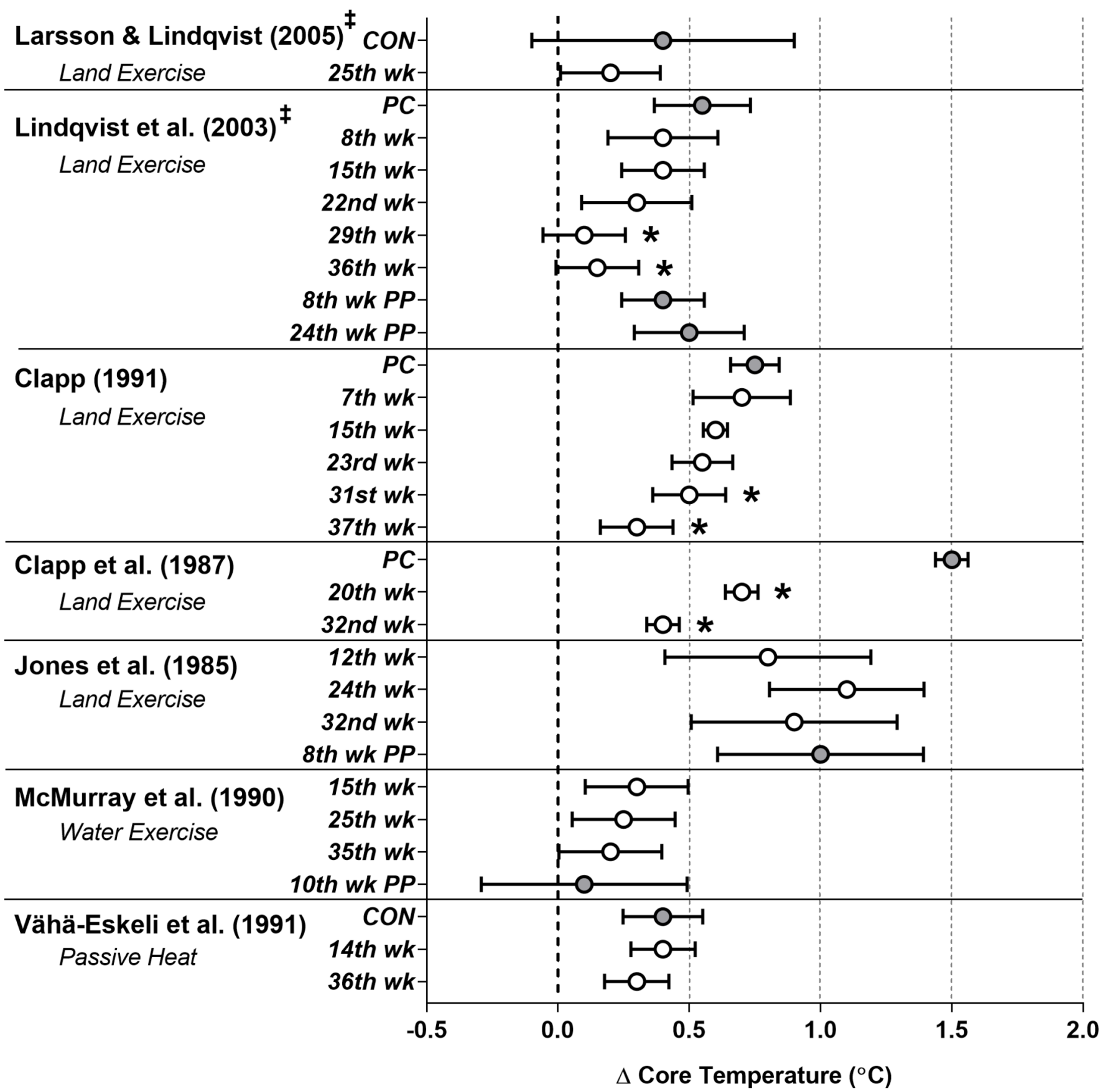

Figure 3 The change in core temperature following land or water immersion exercise, and passive heating in women preconception (PC), across the gestation period and post partum (PP). One study used tympanic temperature as the index of core temperature ( $\ddagger$ ), while the others used rectal temperature. *Significantly lower than PC. CON denotes an independent non-pregnant control group.

During pregnancy, the main avenue for heat transfer between mother and fetus is via the placental wall and uterine blood flow. ${ }^{49}$ With increasing maternal core temperatures, there is evidence of reduced uterine blood flow, ${ }^{50} 51$ although compensatory mechanisms exist to maintain nutrient supply to the fetus. ${ }^{485253}$ Nevertheless, fetal heat balance is entirely dependent on the thermoregulatory capacity of the mother. Thus, progressive hyperthermia will increase the risk of exceeding the teratogenic threshold (maternal core temperature $>39.0^{\circ} \mathrm{C}$ ). The teratogenic threshold is based on the smallest change in core temperature observed to induce fetal defects in animal studies $\left(1.5^{\circ} \mathrm{C}\right.$; assuming a resting internal temperature of $37.5^{\circ} \mathrm{C}$ for humans ${ }^{54}$ ) and supported by retrospective cohort studies in human populations. ${ }^{578}$ In absolute terms, the proposed teratogenic threshold is potentially conservative by more than $1{ }^{\circ} \mathrm{C}$ : animal model evidence in fact suggests a $40^{\circ} \mathrm{C}$ teratogenic threshold. ${ }^{2}{ }^{55-57}$ Nevertheless, the present systematic review found no study in humans reporting core temperatures exceeding $39.0^{\circ} \mathrm{C}$ nor a change in core temperature greater than $1.5^{\circ} \mathrm{C}$ during high-intensity 
exercise (ie, $>70 \% \mathrm{HR}_{\max }$ ) or passive heat stress (figures 2 and 3 , respectively).

An enhanced thermoregulatory capacity during pregnancy has been previously hypothesised. ${ }^{1125-27}$ Indeed, we observed a reduction in the rise in core temperature with progressive pregnancy in some studies (figure 3); however, this pattern may not necessarily be indicative of altered thermoregulatory function due to pregnancy per se as results may be confounded by the experimental design used to compare thermoregulatory responses at different time points in different studies. For example, Lindqvist et $a l^{40}$ employed an exercise intensity ramp protocol without reporting exercise duration. As exercise capacity would presumably be lower during the later stages of pregnancy, ${ }^{59}$ a shorter exercise duration, lower cumulative $\mathrm{H}_{\text {prod }}$ and thus a smaller rise in core temperature would seem likely. Additionally, a larger body size provides a bigger heat sink and a greater potential to dissipate heat by virtue of a larger surface area. ${ }^{60}$ Cramer and $\mathrm{Jay}^{61}$ recently demonstrated a greater change in core temperature in morphologically smaller men when prescribed the same absolute heat production (ie, in watts). It follows that the rise in core temperature during exercise was dependent on the rate of heat production relative to total body mass ( $\mathrm{W} / \mathrm{kg}^{61}$ ), therefore exercise at a fixed heat production at different stages of pregnancy should theoretically lead to smaller rises in core temperature, due to the progressively greater mass. Nevertheless, no study has yet investigated the core temperature response to exercise during pregnancy while accounting for the progressive and often dramatic morphological transformation during pregnancy. As such, the extent that morphological factors independently explain the alterations in the core temperature response during pregnancy remains unclear.

The smallest elevations in core temperature were observed during water-based exercise 373845 (figures 2 and 3). Indeed, the $\sim 25$-fold greater thermal conductivity of water compared with exercise in air (ie, $0.610 \mathrm{~W} / \mathrm{m} / \mathrm{K}$ vs $0.025 \mathrm{~W} / \mathrm{m} / \mathrm{K}$, respectively) hastens non-evaporative heat loss, provided water temperature is lower than skin temperature. Moreover, hydrostatic pressure during water immersion facilitates a greater cardiac filling resulting in a reduced cardiovascular strain compared with landbased exercise for a given exercise intensity in both non-pregnant ${ }^{62}$ and pregnant women. ${ }^{63}$ When pregnant women engaged in a similar intensity exercise out of water, the elevation in core temperature was slightly greater compared with its water-based equivalent (figure 2 ) $^{37}$ although still far below the stated critical core temperature. It is possible that exercising during pregnancy at similar rates of heat production, but in higher ambient air temperatures than previously evaluated, ${ }^{37}$ will result in core temperatures exceeding the teratogenic threshold; in that setting, it may be recommended to limit physical activity to safer environments such as water immersion.

Health guidelines for pregnant women unanimously state that hot water immersion or sauna use should be restricted due to the elevated risk of maternal hyperthermia and the consequent potential impact on fetal development. However, our results suggest that heat stress risk is low (figure 2). It may be unlikely for pregnant women to achieve teratogenic levels of hyperthermia during passive heating due to high levels of discomfort truncating exposure time. ${ }^{64}$ Indeed, the rate of rise in core temperature during hot water immersion is dependent on the mass of the individual. ${ }^{6566}$ Therefore, greater body mass towards the latter stages of pregnancy may mean the exposure duration required to achieve a core temperature exceeding $39.0^{\circ} \mathrm{C}$ could be longer. ${ }^{67}$ With respect to saunas, provided there are no physiological impairments to sweating, the ambient conditions (eg, hot and dry) facilitate high levels of evaporative heat loss. ${ }^{68}$ As demonstrated by Vähä-Eskeli et $a l,{ }^{34}$ the highest mean core temperature in pregnant women following $20 \mathrm{~min}$ of sauna exposure $\left(70^{\circ} \mathrm{C}, 15 \% \mathrm{RH}\right)$ was more than $1.0^{\circ} \mathrm{C}$ lower than the critical $39.0^{\circ} \mathrm{C}$ threshold $\left(37.8^{\circ} \mathrm{C}\right.$; figure 2$)$.

There were three different regions used for measuring core temperature responses: rectal, sublingual and tympanic membrane (figure 2). The clinical gold standard index of core temperature is pulmonary artery temperature. ${ }^{69}$ However, this measurement is highly invasive and impractical. Alternatively, rectal temperature closely correlates with pulmonary artery temperature, ${ }^{69}$ and its measurement is endorsed by the American College of Sports Medicine ${ }^{70}$ for assessing exercise-induced hyperthermia. Less invasive core temperature measurements such as tympanic membrane and sublingual temperature may be $\sim 0.5^{\circ} \mathrm{C}$ lower than rectal measurements during hyperthermia. ${ }^{71}{ }^{72}$ However, regardless of the method used to define core temperature, the highest reported mean tympanic membrane temperature and sublingual temperature following exercise or passive heat stress during pregnancy in the included studies were $37.3^{\circ} \mathrm{C}$ and $36.9^{\circ} \mathrm{C}$, respectively (figure 2 ); more than $1.7^{\circ} \mathrm{C}$ lower than the maternal teratogenic threshold of $39.0^{\circ} \mathrm{C}$.

In this review, the assessment of thermoregulatory responses to exercise during pregnancy was limited to warm or temperate conditions $\left(\sim 25^{\circ} \mathrm{C}\right)$. There may be an association between high ambient temperatures and an increased risk of poor birth outcomes such as preterm delivery ${ }^{73}$ and low birth weight. ${ }^{75}$ However, exercise during pregnancy reduces the risk of infants born at extreme ends of the birth weight range, ${ }^{76}$ protects against preterm birth $^{76} 77$ and improves nutrient delivery to the fetus to support development. ${ }^{52}$ Despite the clear benefits of exercise during pregnancy for mother and unborn child, it remains unclear whether regular physical activity during pregnancy may counterbalance any potential association between high ambient temperatures and birth complications. Thus, more research is needed to identify safe exposure and environmental limits for pregnant women who are physically active in hotter climates, and to elucidate the underlying mechanism responsible for any potential increased risk of poor birth outcomes during prolonged exposure to high ambient temperature.

\section{Limitations}

All included studies were at high risk of allocation bias because of the study design, but we considered allocation bias as a lower threat to the internal validity of this review. Overall, the body of evidence is limited by issues related to intervention, selection and measurement bias. Only one study met the criteria for CEBM level I evidence, and there was especially limited evidence for

What is already known on this topic?

Animal studies have shown that hyperthermia during pregnancy can be teratogenic.

- Pregnant women are advised to avoid heat stress such as exercise in the heat, hot baths or saunas, because of concern about the risk of reaching a core temperature above the proposed teratogenic threshold of $39.0^{\circ} \mathrm{C}$.

- An enhanced thermoregulatory capacity has been hypothesised during pregnancy which could increase thermoprotection to the developing fetus.

- Current guidelines do not clearly define critical heat stress limits that should be avoided. 


\section{What are the new findings?}

- Pregnant women can safely engage in: (1) exercise for up to $35 \mathrm{~min}$ at $80 \%-90 \%$ of their maximum heart rate in $25^{\circ} \mathrm{C}$ and $45 \%$ relative humidity (RH); (2) water immersion $\left(\leq 33.4^{\circ} \mathrm{C}\right.$ ) exercise for up to $45 \mathrm{~min}$; and (3) sitting in hot baths $\left(40^{\circ} \mathrm{C}\right)$ or hot/dry saunas $\left(70^{\circ} \mathrm{C} ; 15 \% \mathrm{RH}\right)$ for up to 20 min, irrespective of pregnancy stage, without reaching a core temperature exceeding the teratogenic threshold.

- The previously hypothesised enhancement of the thermoregulatory capacity of pregnant women is supported by smaller changes in $\mathrm{T}_{\text {core }}$ during exercise/heat exposure as pregnancy progresses. The underlying mechanism is unclear but is likely biophysical in nature, associated with changes in body mass and surface area, and not due to alterations in physiological control.

- The critical exercise (eg, intensity, duration) and environmental (eg, temperature and humidity) characteristics at which the upper limit for maternal $\mathrm{T}_{\text {core }}\left(39.0^{\circ} \mathrm{C}\right)$ is exceeded remains unknown, and requires urgent future research with further refinement incorporating extrinsic (eg, clothing) and intrinsic (eg, acclimation status) factors.

water immersion exercise (grade C) and sauna or hot bath use (grade D). This means that recommendations may change with future research. We only included published full-text articles, which means there is a risk of publication bias. ${ }^{32}$ There is also a risk for language bias since we only included articles written in English. The small body of literature and inconsistency in study design precluded data pooling. Instead we used best evidence synthesis. $^{78}$

\section{CONCLUSION}

Pregnant women may safely engage in: (1) exercise for up to $35 \mathrm{~min}$ at $80 \%-90 \%$ of their maximum heart rate in $25^{\circ} \mathrm{C}$ and $45 \% \mathrm{RH}$; (2) water immersion $\left(\leq 33.4^{\circ} \mathrm{C}\right)$ exercise for up to $45 \mathrm{~min}$; and (3) sitting in hot baths $\left(40^{\circ} \mathrm{C}\right)$ or hot/dry saunas $\left(70^{\circ} \mathrm{C} ; 15 \% \mathrm{RH}\right)$ for up to $20 \mathrm{~min}$, irrespective of pregnancy stage, without reaching a core temperature exceeding the teratogenic threshold.

Contributors NMR, WC, TE, KME and OJ were involved in the conception and design of the systematic review. NMR, WC and TE were responsible for conducting the systematic search. The selection of studies based on the inclusion criteria was primarily conducted by NMR, WC and TE. When disagreement occurred, all authors critically appraised the study inclusion. NMR and WC completed the Cochrane Risk of Bias 2.0 Tool. Data extraction from the included studies was conducted by NMR and independently confirmed by WC and OJ. All authors interpreted the results. NMR, WC and TE drafted the manuscript. OJ and KME critically revised the manuscript. All authors have approved the final version of the manuscript.

Funding NMR is supported by a University of Ottawa Excellence Scholarship, a Natural Sciences and Engineering Research Council Postgraduate Scholarship (PGS-D) and an Endeavour Research Fellowship from the Australian Ministry of Education and Training.

Competing interests None declared.

Provenance and peer review Commissioned; externally peer reviewed.

(c) Article author(s) (or their employer(s) unless otherwise stated in the text of the article) 2019. All rights reserved. No commercial use is permitted unless otherwise expressly granted.

\section{REFERENCES}

1 Edwards MJ. Congenital defects in guinea pigs. Following induced hyperthermia during gestation. Arch Pathol 1967;84:42-8.
2 Edwards MJ. Congenital malformations in the rat following induced hyperthermia during gestation. Teratology 1968;1:173-7.

3 Edwards MJ. Congenital defects in guinea pigs: fetal resorptions, abortions, and malformations following induced hyperthermia during early gestation. Teratology 1969;2:313-28.

4 Miller P, Smith DW, Shepard TH. Maternal hyperthermia as a possible cause of anencephaly. Lancet 1978;1:519-21.

5 Milunsky A, Ulcickas $\mathrm{M}$, Rothman $\mathrm{KJ}$, et al. Maternal heat exposure and neural tube defects. JAMA 1992;268:882-5.

6 Shaw GM, Todoroff $\mathrm{K}$, Velie EM, et al. Maternal illness, including fever and medication use as risk factors for neural tube defects. Teratology 1998;57:1-7.

7 Andersen A-MN, Vastrup P, Wohlfahrt J, et al. Fever in pregnancy and risk of fetal death: a cohort study. The Lancet 2002;360:1552-6.

8 Chambers CD, Johnson KA, Dick LM, et al. Maternal fever and birth outcome: a prospective study. Teratology 1998;58:251-7.

9 Smith DW, Clarren SK, Harvey MA. Hyperthermia as a possible teratogenic agent. J Pediatr 1978;92:878-83.

10 Graham JM, Edwards MJ, Edwards MJ. Teratogen update: gestational effects of maternal hyperthermia due to febrile illnesses and resultant patterns of defects in humans. Teratology 1998:58:209-21.

11 Soultanakis HN. Aquatic exercise and thermoregulation in pregnancy. Clin Obstet Gynecol 2016;59:576-90.

12 Miller MW, Nyborg WL, Dewey WC, et al. Hyperthermic teratogenicity, thermal dose and diagnostic ultrasound during pregnancy: implications of new standards on tissue heating. Int J Hyperthermia 2002;18:361-84.

13 ACOG. ACOG Committee Opinion No. 650: physical activity and exercise during pregnancy and the postpartum period. Obstet Gynecol 2015;126:e135-42.

14 RANZCOG. Exercise during pregnancy. New York, USA: WebMD, 2016.

15 Royal College of Obsteticians and Gynaecologists. RCOG statement on exercise during pregnancy and pre-eclampsia. 2008. https://www.rcog.org.uk/en/news/ rcog-statement-on-exercise-during-pregnancy-and-pre-eclampsia/ (accessed 3 Dec 2016).

16 Carvalho B, Angst MS, Fuller AJ, et al. Experimental heat pain for detecting pregnancyinduced analgesia in humans. Anesth Analg 2006;103:1283-7.

17 Draisci G, Catarci S, Vollono C, et al. Pregnancy-induced analgesia: a combined psychophysical and neurophysiological study. Eur J Pain 2012;16:1389-97.

18 Barakat R, Perales M, Garatachea N, et al. Exercise during pregnancy. A narrative review asking: what do we know? Br J Sports Med 2015;49:1377-81.

19 Kuhrt K, Hezelgrave NL, Shennan AH. Exercise in pregnancy. Obstet Gynaecol 2015;17:281-7.

20 Mudd LM, Owe KM, Mottola MF, et al. Health benefits of physical activity during pregnancy: an international perspective. Med Sci Sports Exerc 2013;45:268-77.

21 Borodulin KM, Evenson KR, Wen F, et al. Physical activity patterns during pregnancy. Med Sci Sports Exerc 2008;40:1901-8.

22 Fell DB, Joseph KS, Armson BA, et al. The impact of pregnancy on physical activity level. Matern Child Health J 2009;13:597-603.

23 Cramp AG, Bray SR. A prospective examination of exercise and barrier self-efficacy to engage in leisure-time physical activity during pregnancy. Ann Behav Med 2009;37:325-34

24 Marquez DX, Bustamante EE, Bock BC, et al. Perspectives of Latina and non-Latina white women on barriers and facilitators to exercise in pregnancy. Women Health 2009;49:505-21.

25 Clapp JF, Wesley M, Sleamaker RH. Thermoregulatory and metabolic responses to jogging prior to and during pregnancy. Med Sci Sports Exerc 1987;19:124-30.

26 Clapp JF. The changing thermal response to endurance exercise during pregnancy. Am J Obstet Gynecol 1991;165:1684-9.

27 Morris SN, Johnson NR. Exercise during pregnancy: a critical appraisal of the literature. J Reprod Med 2005;50:181-8.

28 Nielsen B, Davies CT. Temperature regulation during exercise in water and air. Acta Physiol Scand 1976;98:500-8.

29 Glass S, Dwyer GB. American College of Sports Medicine. ACSM's Metabolic Calculations Handbook. Pennsylvania, USA: Lippincott Williams \& Wilkins, 2007.

30 Higgins J, Sterne J, Savović J, et al. A revised tool for assessing risk of bias in randomized trials. Cochrane Database Syst Rev 2016;10(Suppl 1):CD201601.

31 CEBM. Oxford centre for evidence-based medicine - levels of evidence (March 2009). http://www.cebm.net/oxford-centre-evidence-based-medicine-levels-evidence-march2009/

32 Borjesson-Dunlap SR, Dolny DG, Hughes N, et al. Thermoregulation In Shallow Water Aquatic Exercise During Second Trimester Pregnancy. Medi Sci Sports Exerc 2005;37:S194-5

33 Vähä-Eskeli K, Erkkola R. The effect of short-term heat stress on uterine contractility, fetal heart rate and fetal movements at late pregnancy. Eur J Obstet Gynecol Reprod Biol 1991;38:9-14

34 Vähä-Eskeli K, Erkkola R, Seppänen A. Is the heat dissipating ability enhanced during pregnancy? Eur J Obstet Gynecol Reprod Biol 1991;39:169-74.

35 Vähä-Eskeli KK, Erkkola RU, Seppänen A, et al. Haemodynamic response to moderate thermal stress in pregnancy. Ann Med 1991;23:121-6. 
36 Katz VL, McMurray R, Goodwin WE, et al. Nonweightbearing exercise during pregnancy on land and during immersion: a comparative study. Am J Perinatol 1990;7:281-4.

37 McMurray RG, Katz VL, Meyer-Goodwin WE, et al. Thermoregulation of pregnant women during aerobic exercise on land and in the water. Am J Perinatol 1993;10:178-82.

38 McMurray RG, Berry MJ, Katz VL, et al. The thermoregulation of pregnant women during aerobic exercise in the water: a longitudinal approach. Eur J Appl Physiol Occup Physiol 1990;61:119-23.

39 Jones RL, Botti JJ, Anderson WM, et al. Thermoregulation during aerobic exercise in pregnancy. Obstet Gynecol 1985;65:340-5.

40 Lindqvist PG, Marsal K, Merlo J, et al. Thermal response to submaximal exercise before, during and after pregnancy: a longitudinal study. J Matern Fetal Neonatal Med 2003;13:152-6.

41 Tuffnell DJ, Buchan PC, Albert D, et al. Fetal heart rate responses to maternal exercise, increased maternal temperature and maternal circadian variation. J Obstet Gynaecol 1990;10:387-91.

42 O'Neill ME. Maternal rectal temperature and fetal heart rate responses to upright cycling in late pregnancy. Br J Sports Med 1996:30:32-5.

43 Petrov Fieril K, Glantz A, Fagevik Olsen M. Hemodynamic responses to single sessions of aerobic exercise and resistance exercise in pregnancy. Acta Obstet Gynecol Scand 2016;95:1042-7.

44 Larsson L, Lindqvist PG. Low-impact exercise during pregnancy--a study of safety. Acta Obstet Gynecol Scand 2005;84:34-8.

45 Brearley AL, Sherburn M, Galea MP, et al. Pregnant women maintain body temperatures within safe limits during moderate-intensity aqua-aerobic classes conducted in pools heated up to 33 degrees Celsius: an observational study. $J$ Physiother 2015;61:199-203.

46 Cumming G. Inference by eye: reading the overlap of independent confidence intervals. Stat Med 2009;28:205-20.

47 MacGregor-Fors I, Payton ME. Contrasting diversity values: statistical inferences based on overlapping confidence intervals. PLoS One 2013;8:e56794.

48 Lotgering FK, Gilbert RD, Longo LD. Exercise responses in pregnant sheep: blood gases, temperatures, and fetal cardiovascular system. J Appl Physiol Respir Environ Exerc Physiol 1983;55:842-50.

49 Ziskin MC, Morrissey J. Thermal thresholds for teratogenicity, reproduction, and development. Int J Hyperthermia 2011;27:374-87.

50 Chandler KD, Bell AW. Effects of maternal exercise on fetal and maternal respiration and nutrient metabolism in the pregnant ewe. J Dev Physiol 1981:3:161-76.

51 Clapp JF. Acute exercise stress in the pregnant ewe. Am J Obstet Gynecol 1980;136:489-94.

52 Clapp JF. Influence of endurance exercise and diet on human placental development and fetal growth. Placenta 2006;27:527-34.

53 Curet LB, Orr JA, Rankin HG, et al. Effect of exercise on cardiac output and distribution of uterine blood flow in pregnant ewes. J App/ Physiol 1976;40:725-8.

54 Edwards MJ. Hyperthermia as a teratogen: a review of experimental studies and their clinical significance. Teratog Carcinog Mutagen 1986;6:563-82.

55 Shiota K. Induction of neural tube defects and skeletal malformations in mice following brief hyperthermia in utero. Biol Neonate 1988;53:86-97.

56 Kilham L, Ferm VH. Exencephaly in fetal hamsters following exposure to hyperthermia. Teratology 1976;14:323-6.
57 Arora KL, Cohen BJ, Beaudoin AR. Fetal and placental responses to artificially induced hyperthermia in rats. Teratology 1979;19:251-9.

58 Treuth MS, Butte NF, Puyau M. Pregnancy-related changes in physical activity, fitness, and strength. Med Sci Sports Exerc 2005;37:832-7.

59 Melzer K, Schutz Y, Boulvain M, et al. Physical activity and pregnancy. Sports Medicine 2010:40:493-507.

60 Havenith G, Coenen JM, Kistemaker L, et al. Relevance of individual characteristics for human heat stress response is dependent on exercise intensity and climate type. Eur J Appl Physiol Occup Physiol 1998;77:231-41.

61 Cramer MN, Jay 0. Selecting the correct exercise intensity for unbiased comparisons of thermoregulatory responses between groups of different mass and surface area. J App/ Physiol 2014;116:1123-32.

62 Butts NK, Tucker M, Greening C. Physiologic responses to maximal treadmill and deep water running in men and women. Am J Sports Med 1991;19:612-4.

63 McMurray RG, Katz VL, Berry MJ, et al. Cardiovascular responses of pregnant women during aerobic exercise in water: a longitudinal study. Int J Sports Med 1988;9:443-7

64 Harvey MA, McRorie MM, Smith DW. Suggested limits to the use of the hot tub and sauna by pregnant women. Can Med Assoc J 1981;125:50-3.

65 Cannon P, Keatinge WR. The metabolic rate and heat loss of fat and thin men in heat balance in cold and warm water. J Physiol 1960;154:329-44.

66 Stephens JM, Argus C, Driller MW. The relationship between body composition and thermal responses to hot and cold water immersion. J Hum Perform Extreme Environ 2014;11.

67 Allison TG, Reger WE. Comparison of responses of men to immersion in circulating water at 40.0 and 41.5 degrees C. Aviat Space Environ Med 1998;69:845-50.

68 Leppäluoto J. Human thermoregulation in sauna. Ann Clin Res 1988;20:240-3.

69 Schmitz T, Bair N, Falk M, et al. A comparison of five methods of temperature measurement in febrile intensive care patients. Am J Crit Care 1995;4:286-92.

70 Armstrong LE, Casa DJ, Millard-Stafford M, et al. Exertional heat illness during training and competition. Med Sci Sports Exerc 2007;39:556-72.

71 Easton C, Fudge BW, Pitsiladis YP. Rectal, telemetry pill and tympanic membrane thermometry during exercise heat stress. J Therm Biol 2007:32:78-86.

72 Cranston WI, Gerbrandy J, SNELL ES. Oral, rectal and oesophageal temperatures and some factors affecting them in man. J Physiol 1954;126:347-58.

73 Strand LB, Barnett AG, Tong S. Maternal exposure to ambient temperature and the risks of preterm birth and stillbirth in Brisbane, Australia. Am J Epidemiol 2012;175:99-107.

74 Ha S, Liu D, Zhu Y, et al. Ambient temperature and early delivery of singleton pregnancies. Environ Health Perspect 2017;125:453-9.

75 Wells JC, Cole TJ. Birth weight and environmental heat load: a between-population analysis. Am J Phys Anthropol 2002;119:276-82.

76 Siebel AL, Carey AL, Kingwell BA. Can exercise training rescue the adverse cardiometabolic effects of low birth weight and prematurity? Clin Exp Pharmacol Physiol 2012:39:944-57.

77 Tinloy J, Chuang $\mathrm{CH}$, Zhu J, et al. Exercise during pregnancy and risk of late preterm birth, cesarean delivery, and hospitalizations. Womens Health Issues 2014;24:e99-104.

78 Slavin RE. Best-evidence synthesis: an alternative to meta-analytic and traditional reviews. Educational Researcher 1986;15:5-11. 